\title{
A Study on Structural Applicability of Flyash Bricks with Quarry Dust - an Ecofriendly Alternative for Clay Bricks
}

\author{
Balaraju Sivagnanaprakash $^{1 *}$, Palaniswamy Murthi ${ }^{2}$, Alan Sekaran $^{1}$ \\ 'Department of Civil Engineering, R.V.S Technical Campus, Coimbatore, TamilNadu, India \\ ${ }^{2}$ Vivekananda College of Engineering for Women, Tiruchengode, TamilNadu, India
}

Received: 2 June 2014

Accepted: 3 August 2014

\begin{abstract}
An environmentally sustainable system must maintain a stable resource base avoiding over-exploitation of non-renewable resource systems. Despite the omnipresence of clay brick and fly ash brick, environmental knowledge about its composition and properties is still scarce. This paper studies the hazards in clay brick and advantages in fly ash brick extending with a comparative study on material properties of clay brick and fly ash brick. The fly ash brick (QFAC brick) used for this study is composed of fly ash, quarry dust, and cement. QFAC brick made of fly ash was found to be an eco-friendly material protecting the environment through conservation of topsoil, reduction in carbon emissions, and utilization of waste products like fly ash and quarry dust. Compressive strength, tensile strength, durability, water absorption, impact resistance, and thermal conductivity of QFAC bricks were investigated and compared with conventional clay bricks. The compressive strength of QFAC brick was 15\% higher than that of clay bricks. The flexural strength of QFAC brick was found to be twice that of clay brick. The average water absorption of QFAC brick was as low as $10 \%$. The QFAC brick also possessed high impact resistance and high durability. The thermal conductivity of QFAC brick was as low as that of clay bricks. Hence QFAC bricks are a superior replacement and environmentally sustainable material for clay bricks.
\end{abstract}

Keywords: non-renewable resource, clay brick, QFAC brick, sustainable material

\section{Introduction}

The building construction sector consumes conventional materials such as brick, clay, sand, gravel, and cement, etc., which are generated directly or indirectly from natural resources [1]. Bricks made out of clay are a product that proved its credence since the dawn of civilization. There is a worldwide shortage of natural resource material for the production of conventional bricks [2] These resources are over tapped, unmindful of the conse-

*e-mail: sivagnanaprakash@ymail.com quences, as a result of which barren lagoons have replaced vast stretches of erstwhile fertile land. Advancement in material engineering has yet to render earth obsolete as a building material in both financial- and resource-challenged places [3]. Furthermore, production of conventional brick involves a firing process that generates atmospheric pollution [4]. An issue arising out of these activities plays a vital role in the search for innovative, environmentally friendly, and ready-to-use building composites that combine higher efficiency and quality in the building process with improved thermal resistance [5]. The urge to use eco-friendly, low-cost, and lightweight construction 
materials in the building industry has brought the need to investigate fly ash bricks by benefiting the environment as well as maintaining the material requirements affirmed in the standard [6].

The technology for producing fly ash bricks is easily adaptable by existing clay brick factories. Furthermore, it requires less man power and less area for material processing than in the case of clay brick production [7]. Fly ash brick plays a major role in the abetment of carbon-dioxide, a harmful greenhouse gas mass emission, that is threatening to throw the earth's atmosphere out of balance. This resource material, if not managed properly, may pose environmental challenges [8]. The applications of fly ash includes cellular concrete products, lightweight aggregates, manufacture of cement and asbestos, road construction and embankment, backfill, land development, bricks, blocks, and masonry walls [9]. Fly ash brick reduces up to $30 \%$ the use of cement mortar during laying and plastering, reducing the cost of construction. As no clay is used in the manufacture of fly ash bricks, the scope of efflorescence is negligible. It continues gaining strength as the ages of curing increase. Loss due to breakage under standard working conditions is less than one percent. Fly ash brick has more or less equal weight as that of conventional clay brick. It weighs around 3 to $3.2 \mathrm{~kg}$ per brick. A sustainable environment can be promoted by proper consumption or recycling waste materials. The recent decades have witnessed the increase in number of studies which are being done on recycling the waste, particular on potential alternatives to building materials. Brick with good acid resistivity finds its application in industries such as chemicals, steel, and metalworking, pharmaceuticals, pulp and paper, food and beverage, public utilities, etc. Chemical-resistant brick provides thermal, mechanical, and chemical protection for these kinds of industries. When properly processed, waste materials can effectively function as construction materials that readily meet design specifications [10]. Fly ash utilization in the country is gaining momentum owing to the stringent regulations that India's Ministry of Environment and Forests has stipulated to increase the benefits of using fly ash for various products [11].

\section{Manufacturing QFAC Bricks}

QFAC brick was made out of $40 \%$ class F fly ash, $10 \%$ cement, and $50 \%$ quarry dust. The materials needed for manufacturing QFAC brick are class F Fly ash, ordinary Portland cement, and quarry dust. The materials are mixed thoroughly in dry state in a pan mixture. Water is added to the required consistency and the mixture is fed into the molding machine. In the moulding machine the mixture is compressed hydraulically or mechanically from $125 \mathrm{~mm}$ thickness to $75 \mathrm{~mm}$ thick, getting the size of $230 \times 105 \times 75$. The moulded brick is kept in a closed environment for a day and then stacked in the open air and water cured. Manufactured QFAC bricks are shown in Fig. 1. The chemical composition of the class $\mathrm{F}$ fly ash from a thermal power plant is shown in Table 1.
Table 1. Chemical composition of Class F Fly ash.

\begin{tabular}{|c|c|c|c|}
\hline No. & \multicolumn{2}{|c|}{ Constituent } & Value \\
\hline 1. & Silica & $\mathrm{SiO}_{2}$ & 54.92 \\
\hline 2. & Alumina & $\mathrm{Al}_{2} \mathrm{O}_{3}$ & 23.04 \\
\hline 3. & Iron & $\mathrm{Fe}_{2} \mathrm{O}_{3}$ & 6.62 \\
\hline 4. & Calcium Oxide & $\mathrm{CaO}$ & 3.84 \\
\hline 5. & Magnesium Oxide & $\mathrm{MgO}$ & 2.82 \\
\hline 6. & Loss on Ignition & $\mathrm{LOI} \%$ & 2.88 \\
\hline
\end{tabular}

\section{Methodology}

Due to the scarcity of conventional masonry materials and energy-related issues, alternative masonry materials are promoted [12]. Several studies have focused on improving and stabilizing the development and production of these kinds of bricks in terms of strength, shrinkage, thermal conductivity, and durability to meet building standards [13]

In this paper conventional clay brick of size $230 \times 100 \times 75 \mathrm{~mm}$ and QFAC brick of size $230 \times 105 \times 75 \mathrm{~mm}$ were taken for comparative study. The material properties such as compressive strength, flexural strength, water absorption, impact resistance on bricks, and durability were determined on clay bricks and QFAC bricks during days 7, 14,21 , and 28 of curing.

Compressive strength is an important property of brick and its value should not be less than 3.5 MPa for a standard brick. Water absorption indicates the quantity of water absorbed, proving the brick to be more permeable [14]. The compressive strength and water absorption tests were conducted as per IS 3495 (Parts 1 and 2): 1992 [15].

The flexural strength represents the highest stress experienced within the material at the moment of rupture. The single point load flexural strength test was conducted as per ASTM: C67-13 [16]. Flexural strength of alternative building materials is important to evaluate the performance when subjected to lateral loads due to wind, flood, or any

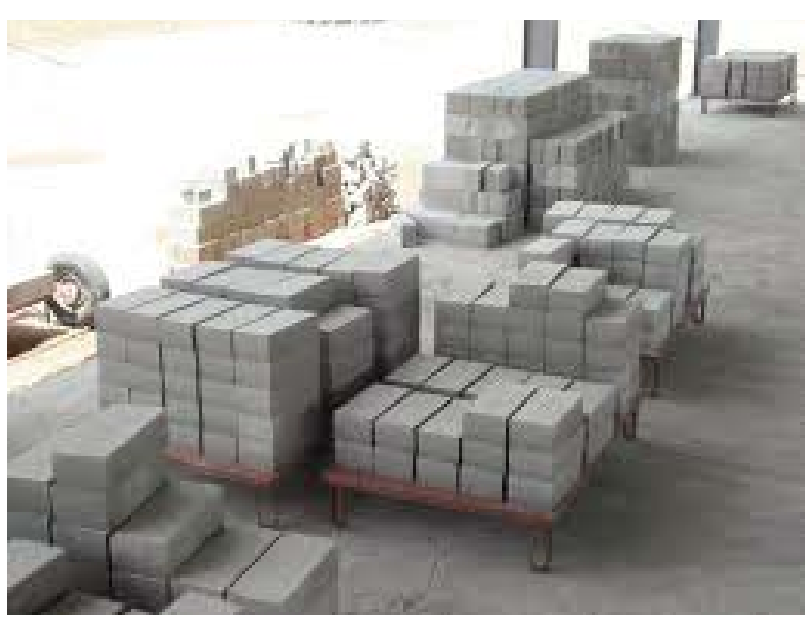

Fig. 1. QFAC bricks. 
other load that can cause out-of-plane bending in a wall. The impact resistance of QFAC and clay bricks was determined by field test.

Thermal conductivity is a measure of the inherent ability to transfer heat. The lower thermal conductivity indicates the greater insulating effect of the material. The thermal conductivity test was conducted on brick walls in order to investigate the heat transfer which has a vital role in environmental thirst. The walls were heated on one side up to $80-90^{\circ} \mathrm{C}$ for a period of 3 hours in the laboratory and the temperature was noted on both sides for the next 3 hours without heating. The sensors were placed on both sides of the wall and the temperature differences were recorded [17].

Finally the durability is determined for both QFAC brick and clay brick using sulphuric acid and hydrochloric acid. Various percentages such as $1 \%, 2 \%$, and $3 \%$ acid solutions were used for conducting the acid resistivity test. The percentage of erosion was represented graphically and the results of QFAC bricks were compared with clay bricks [18].

\section{Results and Discussion}

It is important in masonry design to determine the appropriate ultimate strength of the masonry units. The results of compressive strength, flexural strength, water absorption, impact resistance on bricks, and durability of clay bricks and QFAC bricks were graphed and discussed.

The compressive strength of QFAC brick progressively increased from $3.44 \mathrm{~N} / \mathrm{mm}^{2}$ to $7.95 \mathrm{~N} / \mathrm{mm}^{2}$ during the curing period of 7 days and 28 days, respectively, which is shown in Fig. 2. The compressive strength of clay bricks remained the same $\left(6.75 \mathrm{~N} / \mathrm{mm}^{2}\right)$ for all 28 days of curing. The compressive strength of a 28-day-cured QFAC brick was found to be $15 \%$ higher than the best standard clay brick.

The flexural strength of QFAC brick exhibited a similar result to that of compressive strength. The flexural strength increased from $1.032 \mathrm{~N} / \mathrm{mm}^{2}$ to $2.299 \mathrm{~N} / \mathrm{mm}^{2}$ (Fig. 3) during the curing period from 7 days to 28 days, whereas flexural strength of clay brick remained constant and also the strength resulted higher for QFAC brick when compared to clay bricks. The 28 days cured QFAC bricks had 2 times

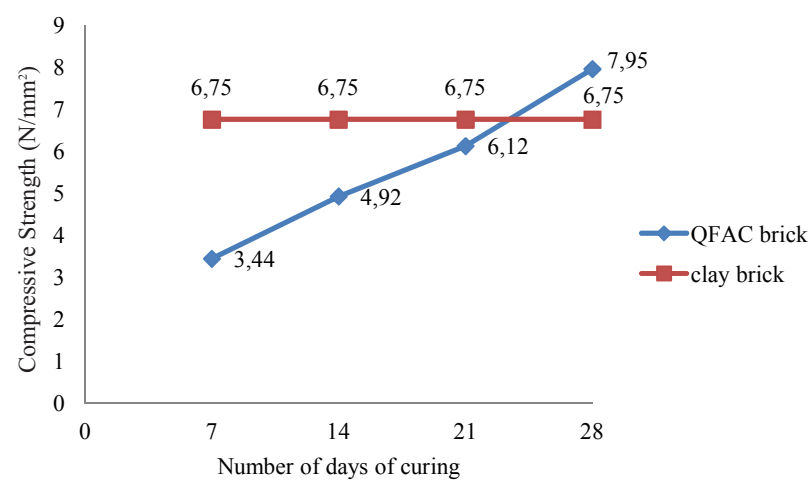

Fig. 2. Comparison of compressive strength in bricks.

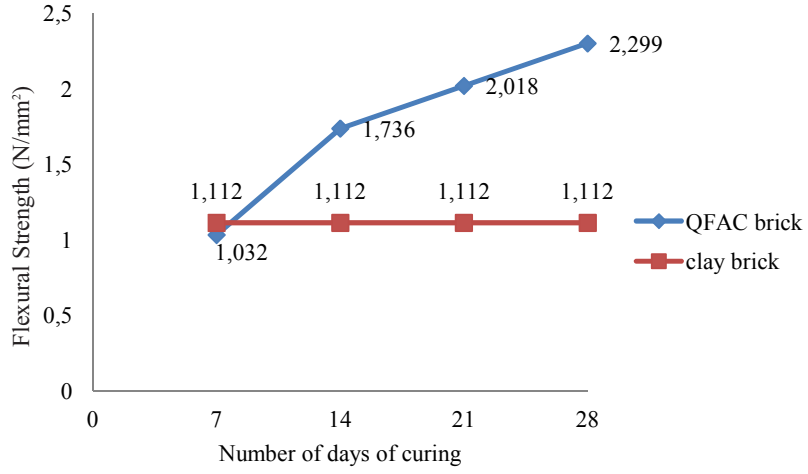

Fig. 3. Comparison of flexural strength in bricks.

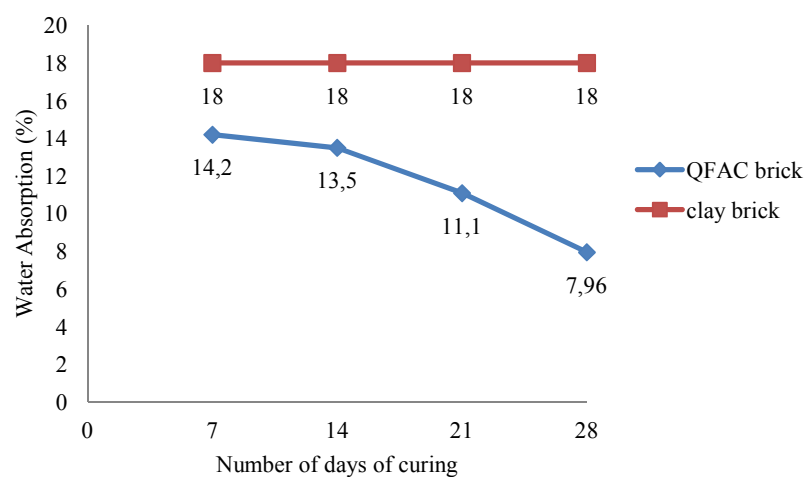

Fig. 4. Comparison of water absorption in bricks.

higher flexural strength than the clay bricks. From the result it is evident that the fly ash brick masonry can withstand higher flexural load than the clay bricks. Water absorption is a major factor for the durability of bricks. The high absorption of water would contribute to a rapid deterioration of the material. Water absorption of QFAC bricks was lower compared to clay brick during all the days of testing; this may result in a reduction of damping. The water absorption of QFAC bricks decreased from $14.2 \%$ to $7.96 \%$ as the days of curing increased from 7 days to 28 days (Fig. 4), whereas that of clay brick remained the same at $18 \%$. Brick with $8 \%$ average water absorption is 10 times more durable in resisting salt attack than that with water absorption of $20 \%$. To mitigate the adverse effects but at the same time retain the advantages associated with porosity, the water absorption of facing bricks for masonry brickwork should preferably be maintained at around $10 \%$. This explains why brick walls require comparatively minimum maintenance in the course of time.

In addition, from the field impact resistance test result on both clay brick and QFAC brick, the number of broken pieces was found to be 3 for QFAC bricks and that for Clay bricks was 7 (Fig. 5). From this result it can be inferred that QFAC bricks have better impact resistance than clay bricks.

Thermal conductivity is an important criterion of masonry materials, as the thermal conductivity influences the use of the material in engineering applications. The thermal conductivity of a brick is the rate at which a brick conducts heat [19]. Decreasing the thermal conductivity of building material will lead to significant savings in the con- 
sumed energy by heating and air-conditioning [20]. The thermal conductivity test results showed a similar behavior in both clay bricks and QFAC bricks (Fig. 6). This implies that the thermal property of QFAC bricks was equally good when compared with conventional clay bricks. The durability of QFAC brick was also found to be higher when compared to clay brick. The loss of weight exhibited by QFAC brick varied from $2.169 \%$ to $2.94 \%$, which was less when compared to clay brick for all concentrations of hydrochloric acid used - namely 1\%, 2\%, and 3\% (Fig. 7). A similar behavior was observed with QFAC brick during a durability test using hydrochloric acid, the loss of weight varied from $1.11 \%$ to $2.1 \%$ (Fig. 8 ), which was less when compared with the percentage of erosion of clay brick. It was confirmed that the mechanical properties of QFAC brick increases as it gets aged, thus indirectly increasing the durability of the structure.

\section{Conclusion}

Based on various tests conducted on clay brick and QFAC brick $(230 \times 105 \times 75 \mathrm{~mm})$, it was concluded that the QFAC brick was comparatively better in all aspects such as strength, economy, and environment. QFAC bricks consume less energy during the manufacturing process and do not emit greenhouse gases. These are durable, and have low water absorption and low thermal conductivity. The compressive strength of QFAC brick is $7.95 \mathrm{~N} / \mathrm{mm}^{2}$ at 28 days of curing, which is $15 \%$ higher than that of conventional

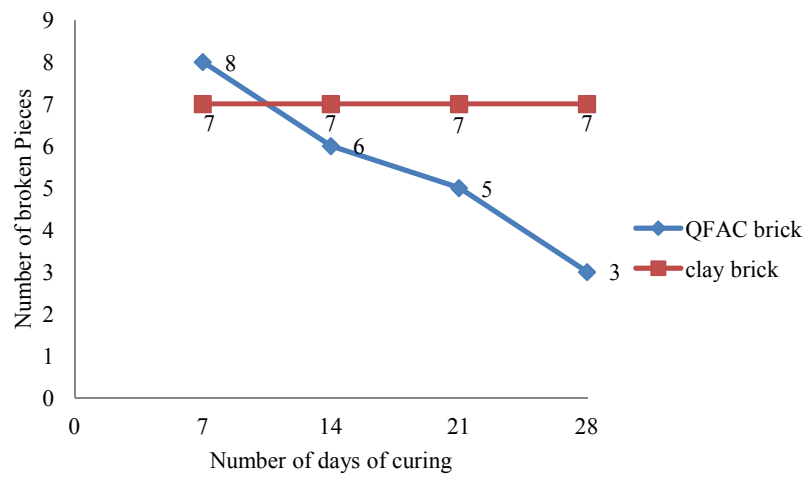

Fig. 5. Comparison of impact resistance on bricks.

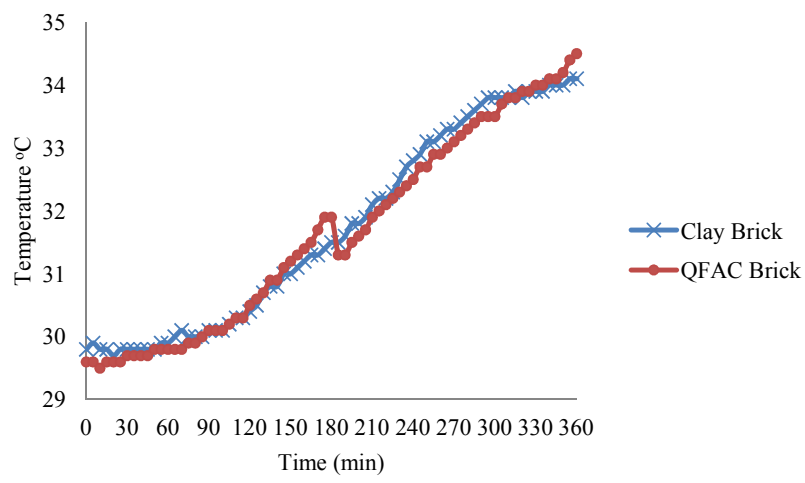

Fig. 6. Comparison of thermal conductivity of bricks.

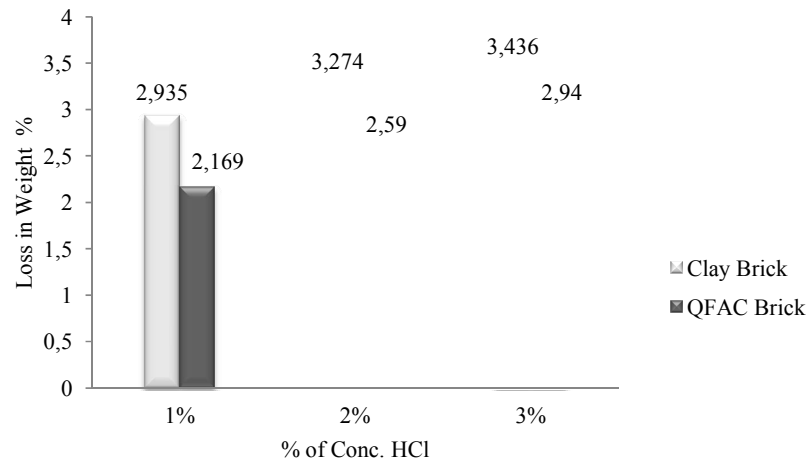

Fig. 7. Comparison of durability under various $\%$ of $\mathrm{HCl}$.

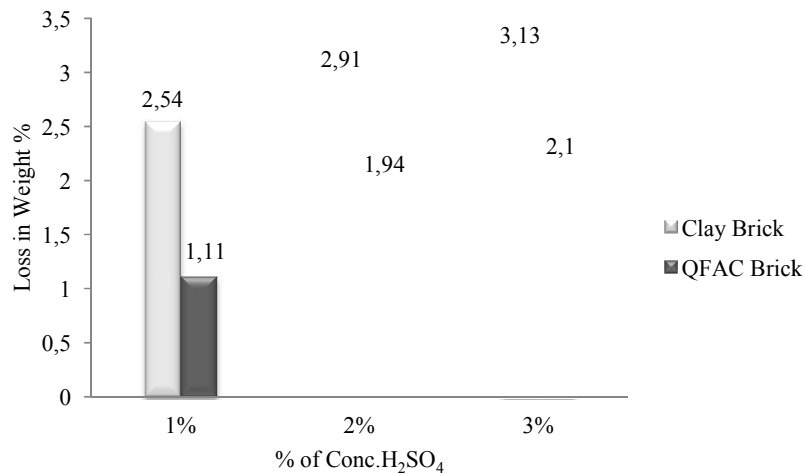

Fig. 8. Comparison of durability under various $\%$ of $\mathrm{H}_{2} \mathrm{SO}_{4}$

clay bricks. The 28 days flexural strength of QFAC brick $\left(2.299 \mathrm{~N} / \mathrm{mm}^{2}\right)$ was twice than that of conventional clay bricks. The water absorption of QFAC bricks decreased gradually from $14.2 \%$ for 7 days curing to $7.96 \%$ for 28 days curing, indicating favorable values within $20 \%$ of its self weight. The thermal conductivity of the QFAC bricks resulted in negligible differences compared to clay bricks and maintained the same standard. The QFAC bricks possess high durability and good impact resistance. Hence the QFAC brick of attempted material, composition, and size is an environmentally sustainable and an amiable alternative to clay bricks.

\section{References}

1. SHRIKANT S., JAHAGIRDAR., SHRIHARI S., MANU B. Utilization of Textile Mill Sludge in Burnt Clay Bricks. International Journal of Environmental Protection, 3, (5), 6, 2013.

2. ZHANG L. Production of bricks from waste materials - A Review. Construction and Building Materials, 47, 643, 2013.

3. CHAN C.-M. Effect of Natural Fibres Inclusion in Clay Bricks: Physico-Mechanical Properties. International Journal of Civil and Environmental Engineering. 3, (1), 51, 2011.

4. VILLEDA MUNOZ G., CASTANEDA MIRANDA A., PLESS R. C., VEGA DURAN J. T., PINEDA PINON J. Clay-brick firing in a high-temperature solar furnace. Ingenieria Investigacion Technologia, 12, (4), 395, 2010.

5. TURGUT P., YESILATA B. Physico-mechanical and thermal performances of newly developed rubber-added bricks. Energ. Buildings, 40, 679, 2008. 
6. SHAKIR A. A., NAGANATHAN S., BIN MUSTAPHA K N. Development of Bricks From Waste Material: A Review Paper. Australian Journal of Basic and Applied Sciences, 7, (8), 812, 2013

7. KAYALI O. High performance bricks from fly ash, World of coal ash (WOCA), Lexington, Kentucky, April 11-15, 2005.

8. SALLA S., PITRODA J. Comparative Review on: Effect of Natural Fibres Inclusion in Fly Ash Bricks. Indian Journal of Research, 1, (12), 62,

9. SHAKIR A. A., NAGANATHAN S., BIN MUSTAPHA K. $\mathrm{N}$. Effect of quarry dust and billet scale additions on the properties of fly ash bricks. IJST, Transactions B of Civil Engineering, 38, 51, 2014.

10. KADIR A. A., ZAHARI N. A. M., MARDI N. A Utilization of Palm Oil Waste into Fired Clay Brick. Advances in Environmental Biology, 7, (12), 3826, 2013.

11. SUHAS V., PATIL, SURYAKANT C. NAWLE, SUNIL J KULKARNI Industrial Applications of Fly ash: A Review. International Journal of Science, Engineering and Technology Research, 2, (9), 2013.

12. JAYASINGHE C., MALLAWAARACHCHI R.S. Flexural strength of compressed stabilized earth masonry materials. Mater. Design. 30, 3859, 2009.

13. SALLEHAN ISMAIL, ZAITON YAACOB Properties of Laterite Brick Reinforced with Oil Palm Empty Fruit Bunch Fibres. Pertanika J. Sci. \& Technol. 19, (1), 33, 2011.
14. PAVIA S., HANLEY R. Flexural bond strength of natural hydraulic lime mortar and clay brick. Mater. Struct. 43, 913, 2010.

15. IS 3495 (Part 1 to 4): 1992, Indian standard Methods of tests of Burnt Clay Building Bricks.

16. ASTM C67 - 13, Standard Test Methods for Sampling and Testing Brick and Structural Clay Tile.

17. CUSTODIO-GARCIA E., SEBASTIAN P.J., CAMPOS ALVAREZ J., TREVINO PLACIOS C. G., ZARATE E. A., CORDOVAA Q. A., DE LA O-LEON H. Solar conduction heat transfer in fired clay bricks. Sol. Energ. Mat. Sol. C. 88, 169, 2005.

18. JEYASEHAR A. C., SARAVANAN G., RAMAKRISHNAN A.K., KANDASAMY S. Strength and durability studies on fly ash based geopolymer bricks. Asian Journal of Civil Engineering. 14, (6), 797, 2013.

19. KADIR A. A., MOHAJERANI A., RODDICK F., BUCKERIDGE J. Density, Strength, Thermal Conductivity and Leachate Characteristics of Light-Weight Fired Clay Bricks Incorporating Cigarette Butts. World Academy of Science, Engineering and Technology. 3, 1312, 2009.

20. ALI M. OTHMAN Experimental Investigations of the Effect of Some Insulating Materials on the Compressive Strength, Water Absorption and Thermal Conductivity of Building Bricks. Jordan Journal of Mechanical and Industrial Engineering. 4, (4), 443, 2010. 
